\title{
The impact of social media promotion with infographics and podcasts on research dissemination and readership
}

Brent Thoma, MD, MA, MSc*; Heather Murray, MD, $\mathrm{MSc}^{\dagger}$; Simon York Ming Huang, $\mathrm{MSc}^{*}$; William Ken Milne, MD, MSc ${ }^{\ddagger}$; Lynsey J. Martin, MD, MHPE*; Christopher M. Bond, MD ; Rohit Mohindra, MD, MASc ${ }^{\text {I }}$; Alvin Chin, MD, MSc**; Calvin H. Yeh, MD, PhD ${ }^{\dagger+}$; William B. Sanderson, MD ${ }^{\ddagger \ddagger}$; Teresa M. Chan, MD, MHPE**

\section{ABSTRACT}

Objective: In 2015 and 2016, the Canadian Journal of Emergency Medicine (CJEM) Social Media (SoMe) Team collaborated with established medical websites to promote CJEM articles using podcasts and infographics while tracking dissemination and readership.

Methods: CJEM publications in the "Original Research" and "State of the Art" sections were selected by the SoMe Team for podcast and infographic promotion based on their perceived interest to emergency physicians. A control group was composed retrospectively of articles from the 2015 and 2016 issues with the highest Altmetric score that received standard Facebook and Twitter promotions. Studies on SoMe topics were excluded. Dissemination was quantified by January 1, 2017 Altmetric scores. Readership was measured by abstract and full-text views over a 3-month period. The number needed to view (NNV) was calculated by dividing abstract views by full-text views.

Results: Twenty-nine of 88 articles that met inclusion were included in the podcast (6), infographic (11), and control (12) groups. Descriptive statistics (mean, 95\% confidence interval) were calculated for podcast (Altmetric: 61, 42-80; Abstract: 1795, 1135-2455; Full-text: 431, 0-1031), infographic (Altmetric: 31.5, 19-43; Abstract: 590, 361-819; Full-text: 65, 33-98), and control (Altmetric: 12, 8-15; Abstract: 257, 159-354; Full-Text: 73, 38-109) articles. The NNV was 4.2 for podcast, 9.0 for infographic, and 3.5 for control articles.

Discussion: Limitations included selection bias, the influence of SoMe promotion on the Altmetric scores, and a lack of generalizability to other journals.

Conclusion: Collaboration with established SoMe websites using podcasts and infographics was associated with increased Altmetric scores and abstract views but not full-text article views.
RÉSUMÉ

Contexte: En 2015-2016, l'équipe des médias sociaux du Journal canadien de la médecine d'urgence a travaillé en collaboration avec des équipes de sites Web médicaux établis afin de faire la promotion d'articles du Journal par la baladodiffusion et l'infographie, et de suivre l'évolution de la diffusion et du lectorat.

Méthode: Le choix des articles du Journal, parus dans les sections Original Research et State of the Art en vue de la promotion par la baladodiffusion et l'infographie a été effectué par l'équipe des médias sociaux d'après sa perception de l'intérêt pour les médecins d'urgence. Un groupe témoin d'articles parus dans les numéros de 2015 et de 2016 et ayant fait l'objet de la promotion habituelle dans Facebook and Twitter a été constitué de manière rétrospective à l'aide des scores Altmetric les plus élevés. Les études portant sur des sujets liés aux médias sociaux ont été écartées. En ce qui concerne la diffusion, elle a été quantifiée selon les scores Altmetric en date du $1^{\mathrm{er}}$ janvier 2017. Quant au lectorat, il a été mesuré à l'aide du nombre de visionnements de résumés ou d'articles en version intégrale sur une période de 3 mois. Le nombre requis de visionnements (NRV) a été calculé par la division du nombre de visionnements de résumés par celui d'articles en version intégrale.

Résultats: Sur 88 articles qui respectaient les critères d'inclusion, 29 ont été répartis comme suit : 6 dans le groupe de la baladodiffusion, 11 dans celui de l'infographie et 12 dans le groupe témoin. Des statistiques descriptives (moyenne : IC à $95 \%$ ) ont été calculées pour la baladodiffusion (score Altmetric : $61 \rightarrow 42-80$; résumé : $1795 \rightarrow$ 1135-2455; texte en version intégrale : $431 \rightarrow 0-1031$ ), pour l'infographie (score Altmetric : $31,5 \rightarrow 19-43$; résumé : $590 \rightarrow 361-819$; texte en version intégrale : $65 \rightarrow 33-98$ ) et pour les articles témoins (score Altmetric : $12 \rightarrow 8-15$; résumé : $257 \rightarrow 159-354$; texte en version

\footnotetext{
From the *Department of Emergency Medicine, University of Saskatchewan, Saskatoon, SK; †Department of Emergency Medicine, Queen's University, Kingston, ON; ¥Division of Emergency Medicine, Western University, London, ON; §Department of Emergency Medicine, University of Calgary, Calgary, AB; ๆDepartment of Emergency Medicine, Jewish General Hospital, Montreal QC; **Division of Emergency Medicine, McMaster University, Hamilton, ON; ††Division of Emergency Medicine, University of Toronto, Toronto, ON; and the ¥¥Department of Emergency Medicine, University of Kentucky, Lexington, KY.
}

Correspondence to: Dr. Brent Thoma, Department of Emergency Medicine, University of Saskatchewan, Room 2646, Box 16, 103 Hospital Drive, Saskatoon, SK S7N 0W8; Email: brent.thoma@usask.ca 
intégrale : $73 \rightarrow 38-109)$. Le NRV a atteint 4,2 pour la baladodiffusion; 9,0 pour l'infographie et 3,5 pour les articles témoins.

Discussion: Les points faibles comprenaient un biais de sélection, I'influence de la promotion des médias sociaux sur les scores Altmetric et le manque de généralisation à d'autres revues.

Conclusion: La collaboration avec des équipes de sites Web de médias sociaux à l'aide de la baladodiffusion et de l'infographie a été associée à une augmentation des scores Altmetric ainsi que du nombre de visionnements des résumés mais pas à une augmentation du nombre de visionnements des articles en version intégrale.

Keywords: knowledge translation, social media, online educational resources, infographics, podcasts

\section{INTRODUCTION}

Communities of practice are groups of people who share ideas and artifacts related to a common interest or passion, which they use to enhance their practice. $^{1,2}$ As communities of practice develop online in emergency medicine, ${ }^{1,3}$ social media (SoMe) is rapidly evolving into a critical tool for the dissemination of new scholarly material and resources for practitioners. ${ }^{4,5}$ It is becoming important for authors, research groups, and journals to do more than simply publish research; they are increasingly tasked with assisting in the dissemination and knowledge translation of their work. ${ }^{5}$ This is especially important in the field of emergency medicine, where SoMe tools, including Twitter, Facebook, blogs, and podcasts, are frequently used by trainees and practitioners. ${ }^{6-8}$ As an example of the effective use of SoMe to disseminate new knowledge, a recent infographic initiative run by BoringEM.org (now CanadiEM.org) translated the 2015 American Heart Association guidelines into a collection of infographics. ${ }^{9}$ The blog post where these graphics are housed has been viewed well over 60,000 times. Although this reach is impressive, it underestimates their impact, because they were also downloaded and shared through private SoMe platforms (e.g., Facebook, WhatsApp).

Because emergency medicine's online community of practice is comfortable accessing and using these resources, we anticipated that articles promoted using podcasts and blog-based infographics will be more broadly disseminated to increase awareness of new research. Although a significant amount of literature has been published on the utilization ${ }^{6-8}$ and quality ${ }^{10-13}$ of such resources, relatively little has been done to determine which strategies are the most effective for increasing dissemination and readership of medical research. Mixed results have been found in the investigation of promotion on Twitter, ${ }^{14-16}$ and no studies to date have formally investigated the effects of collaborative promotion with popular SoMe-based websites.
The Canadian Journal of Emergency Medicine (CJEM) created a SoMe Team in 2014. The SoMe Team promoted CJEM articles on the journal's Facebook and Twitter accounts and trialed a process of creating and disseminating secondary resources to promote selected CJEM publications. The CanadiEM website was enlisted to create and publish infographics describing CJEM articles. The Skeptics' Guide to Emergency Medicine (SGEM) website agreed to critically appraise CJEM publications and discuss them in a series of podcasts and review articles. ${ }^{17,18} \mathrm{We}$ performed a retrospective analysis to quantify the impact of these efforts on the dissemination and readership of CJEM articles.

\section{METHODS}

The CJEM SoMe Team consisted of the CJEM SoMe editors (TM, BT, RM), a group of trainees ( $\mathrm{SH}, \mathrm{LM}, \mathrm{CY}$, $\mathrm{AC}$ ), and two consultant emergency physicians (WBS, HM), all of whom were recruited to contribute to its work. Its exact composition varied over time with members added on an ad hoc basis as needs were identified.

\section{Article selection}

Articles published in the 2015 and 2016 issues of CJEM in the "Original Research" and "State of the Art" sections were considered for SoMe promotion with the creation of secondary resources (infographics and podcasts). Studies on SoMe topics were excluded. No article was selected for more than one promotional technique.

One article was promoted via podcast in each of the six issues of CJEM published in 2016. The article was selected from each issue by group consensus based upon their perceived interest to emergency physicians as determined by the SGEM team (KM and $\mathrm{CB}$ ) and the CFEM SoMe editors (TC, BT, RM). 
Articles promoted via the creation of infographics were published in the 2015 and 2016 issues of CJEM. From January 2015 through June 2016, articles were selected on an ad hoc basis by the CJEM SoMe editors based upon their perceived interest to emergency physicians. From July 2016 through November 2016, four articles per issue were selected by the SoMe team, and two were randomized to receive an infographic as part of an ongoing randomized trial external to this study. Infographic articles were always selected after the podcast article had been selected.

Control group articles were selected retrospectively by identifying the article with the highest Altmetric score as of January 1, 2017, from each of the 12 CJEM issues published in 2015 and 2016, which was not promoted by infographic or podcast.

\section{Interventions}

Three SoMe promotional strategies were used. Each process is outlined in Figure 1.

All articles included in the study received standard SoMe promotion. This included a tweet from the journal's Twitter account (@CJEMonline) and a post on the CFEM Facebook page containing a link to the article and a brief (1- to 2-sentence) summary of its

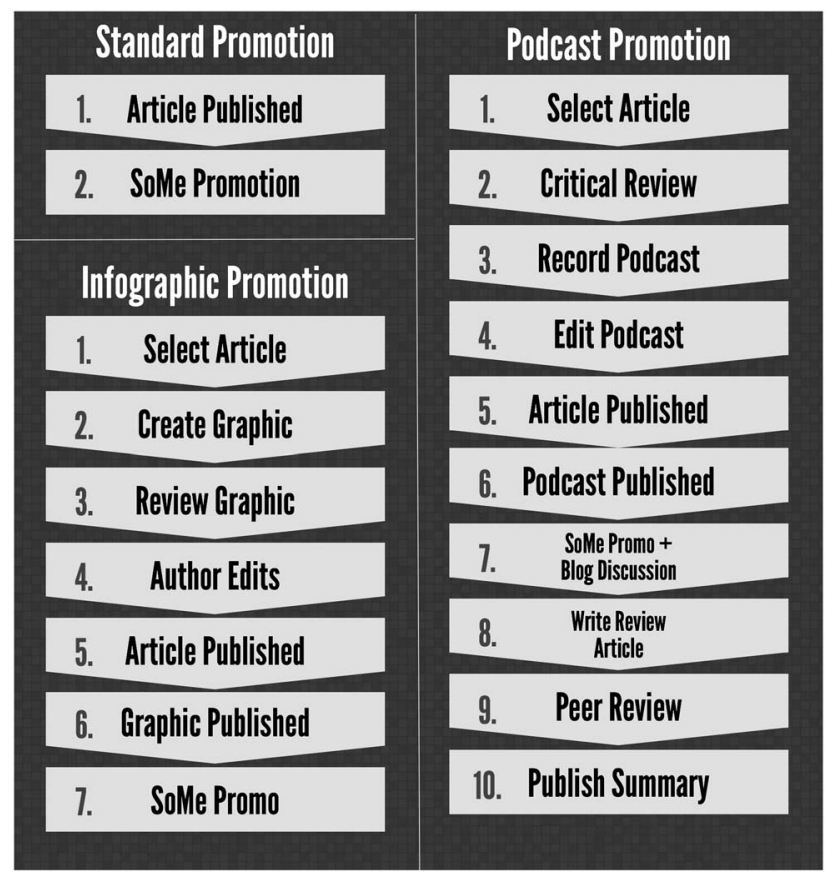

Figure 1. Graphical representation of the social media promotion process for control, infographic, and podcast groups. contents. In some cases, the SoMe posts of the control articles included screen captures of the articles' abstracts. The use of screen-captured images for control articles increased throughout the study period as the importance of images in SoMe promotion was recognized by the SoMe Team.

Infographics were published as part of a collaboration between CJEM and CanadiEM (https://canadiem.org). CanadiEM is a nonprofit Canadian website hosting emergency medicine content freely accessible to all users. The infographic creation process evolved over time to allow the authors of the articles promoted by the infographics to review them prior to publication. The infographic and article were also promoted on the CanadiEM and CFEM Twitter and Facebook accounts.

Podcasts were published as part of a collaboration between CJEM and the SGEM podcast (www.thesgem. com). The SGEM is a nonprofit Canadian website that critically appraises new and recent research using downloadable podcasts linked with online content. Each article was featured on a Hot Off the Press (HOP) series SGEM podcast and made freely available (in full text and as a PDF download) from the CJEM website for one month after publication. In addition, listeners and followers of the SGEM and CJEM SoMe accounts were directed to the SGEM blog to participate in a discussion of this article. Following the publication of the podcast, the SGEM team drafted a summary of the podcast and SoMe commentary that was subsequently published in CJEM. ${ }^{17,18}$

\section{Dissemination and readership}

The metrics used to quantify dissemination and readership were selected by the SoMe editors in collaboration with the CJEM Editor-in-Chief.

Dissemination was measured using each article's Altmetric score as of January 1, 2017. Altmetric scores are proprietary metrics calculated for scientific research articles that amalgamate the discussion of articles across various platforms to provide an estimate of their disseminative impact. ${ }^{19}$

Readership was quantified using abstract page views ${ }^{20}$ and full-text page views on the CJEM website in the month of formal publication and the two subsequent months. This timeline was selected to ensure that the full impact of SoMe promotion was included while standardizing the time interval across issues. An abstract view was recorded each time that an article's abstract 
page was loaded on the CJEM website. A full-text view was recorded each time that a full-text article page was loaded and each time that a PDF version of the article was downloaded from the CJEM website.

To quantify how frequently abstract viewers loaded a full-text version of an article promoted by each of the SoMe promotional strategies, the number needed to view (NNV) was conceived. The NNV was calculated by dividing the mean number of abstract views by the mean number of full-text views to provide a relative estimate of the frequency with which an abstract viewer reviews the full article for each promotional method.

\section{Analysis}

Descriptive statistics were calculated using Microsoft Excel (2016). Altmetric scores, abstract views, and full-text views were reported as the mean $+/$ - interquartile range.

\section{RESULTS}

The selection of the articles within the control, infographic, and podcast groups is outlined in Figure 2. The average abstract views, full-text views, Altmetric scores, and NNV are presented in Table 1.

\section{DISCUSSION}

In previous editorials, we hypothesized that SoMe could effectively disseminate new scientific findings. ${ }^{4,5}$ Contrary to other journal-level analyses, which focused on SoMe promotion with social networks such as Twitter and Facebook, ${ }^{14,15}$ we considered this level of SoMe promotion to be standard for all articles and investigated the additional impact of creating infographics and podcasts. We believe that we are the first to demonstrate increased abstract readership using these modalities and to investigate the impact of SoMe-directed abstract readership on article readership through the calculation of a NNV.

Although both podcast and infographic strategies significantly increased article Altmetric scores and abstract readership, they did not significantly increase full-text readership. This was true even for articles promoted by podcasts, where full-text readership was easier because the articles were freely accessible during the month of dedicated SoMe promotion. This is concerning because it demonstrates that, although SoMe increased the dissemination of research findings, the research was not likely to have been read in detail. Because the appropriate interpretation of research requires critical appraisal, this finding suggests that the

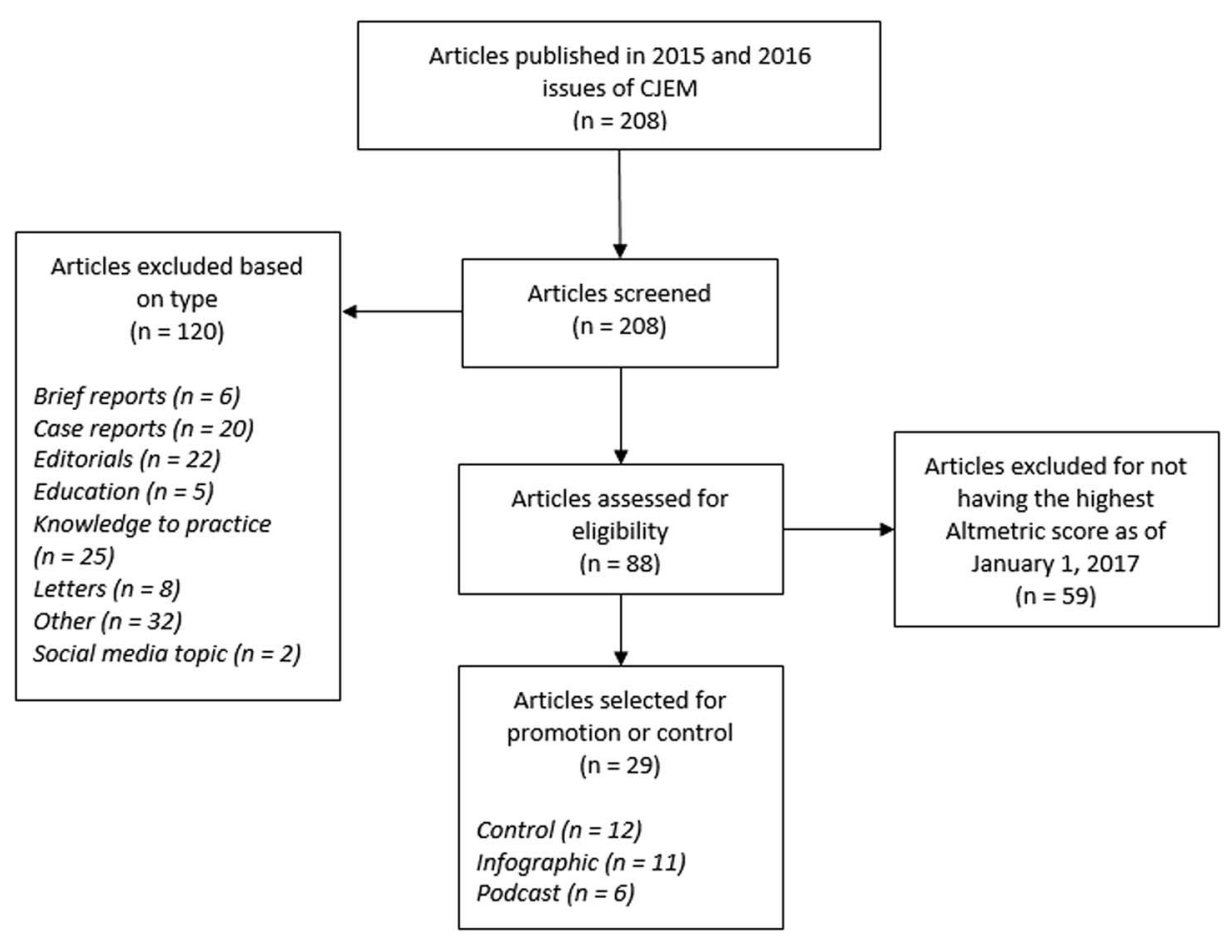

Figure 2. Flowchart outlining CJEM article selection for promotion in the control, infographic, and podcast groups. 


\begin{tabular}{|c|c|c|c|c|}
\hline & $\begin{array}{l}\text { Abstract views } \\
\text { N }(95 \% \mathrm{Cl})\end{array}$ & $\begin{array}{l}\text { Full-text views } \\
\text { N (95\% Cl) }\end{array}$ & $\begin{array}{c}\text { Altmetric score } \\
\text { N }(95 \% \mathrm{Cl})\end{array}$ & NNV \\
\hline Control & 257 (159-354) & 73 (38-109) & $12(8-15)$ & 3.5 \\
\hline Infographic & $590(361-819)$ & $65(33-98)$ & $32(19-43)$ & 9.0 \\
\hline Podcast & $1,795(1,135-2,455)$ & $431(0-1,031)$ & $61(42-80)$ & 4.2 \\
\hline
\end{tabular}

SoMe promotional strategies did not result in deep review of the research and that there is a risk that SoMe promotion could be harmful if a study's results are presented inaccurately. This finding is more concerning for infographics than podcasts because infographics generally provide a shorter and more superficial overview of research, whereas podcasts often include a more extensive critical appraisal. Medical educators with prominent SoMe platforms should be vigilant in ensuring their accuracy and aware that the results that they promote are likely to be viewed without further appraisal of the primary literature.

On the other hand, awareness is an important first step in knowledge translation because clinicians unaware of practice-changing literature cannot change their practice. Awareness is the first step of Pathman's knowledge translation model, which includes three additional steps: agreement, adoption, and adherence. ${ }^{21,22}$ Beyond awareness, SoMe may foster agreement by amplifying the influence of opinion leaders $^{23}$ and disseminating well-designed resources. The final steps of Pathman's model, adoption and adherence, require decisions to be made at a local institution and may involve the development of new policies, the purchase of equipment, the availability of medications, practice auditing, and feedback. ${ }^{21}$ These steps are less likely to be influenced by SoMe promotional initiatives. In general, their effect is difficult to target at a specific clinician group, which implies that it will be more effective for national or international initiatives than local implementation.

Based on our results, we would recommend that journals and researchers continue using various methods of SoMe promotion. However, there is a need for increased incorporation of experimental study designs to better determine what strategies work most effectively in various contexts. In addition to the use of Twitter, Facebook, infographics, blog posts, and podcasts, virtual abstracts are an intriguing new modality that requires study. ${ }^{24}$ Each of these modalities has different costs and may have different effects on dissemination, readership, and translation of research findings. Our results support collaboration with established SoMe as part of these efforts. Moving beyond Altmetric scores, the impact of a SoMe strategy on abstract and article readership should also be quantified with metrics such as page views and downloads. Although it has not been previously described, we believe that the NNV is a promising metric for use in comparing changes in abstract and full-text readership secondary to SoMe promotion.

Of note, only the podcast strategy incorporated the use of a discussion forum which, in addition to increasing article dissemination, required active engagement with the article from discussion participants. Because active learning has been found to be superior to passive learning in multiple contexts, ${ }^{25-27}$ it is likely that more interactive strategies, such as online discussions and journal clubs, ${ }^{28,29}$ would increase knowledge uptake and retention. However, an investigation of this hypothesis was outside of the scope of this study and should be considered for investigation in future research. While dissemination and readership were investigated in this study, the impact of SoMe on practice change is unlikely to relate directly to these metrics.

\section{LIMITATIONS}

Selection bias was introduced through the selection of articles for the intervention groups that were felt to be of greatest interest to the emergency medicine community. We attempted to ameliorate this by comparing their results to the strongest possible control group. The impact of podcasts is particularly at risk given that the podcast articles were selected from each issue first.

Because of the unique circumstances surrounding the SoMe promotion by CJEM, the results presented may not be generalizable. Specifically, emergency medicine has an established virtual community of practice, ${ }^{3,30}$ the CJEM SoMe Team included two of the most influential 
emergency medicine physicians on Twitter, ${ }^{31}$ websites with prominent pre-existing SoMe followings (CanadiEM and SGEM) ${ }^{32}$ were used for dissemination, and the SoMe Team was able to leverage the study authors to create the infographics at negligible monetary costs.

While we believe that it will be useful for comparing the success of promotion using various SoMe modalities, the NNV is a new and untested metric. It is likely to vary based on interest in the article, the impact of the journal, the quality of the resource, and the effectiveness of its promotion.

The comparison of full-text views was limited by their poor accessibility beyond those with memberships in the Canadian Association of Emergency Physicians (CAEP) or those who work at institutions with subscriptions to CJEM. However, there was no significant difference in full-text views in articles promoted by podcasts that were freely accessible for a full month. This could have been due to a lack of power.

CJEM changed publishers and website domains in January 2015 and had its Web platform upgraded in September 2016. The changing of publishers/domains likely decreased viewership metrics, whereas the upgrade of the Web platform may have increased them. These changes likely benefited the intervention groups as more articles were promoted in the latter half of 2016.

The readership metrics for all promotional modalities are likely underreported because they did not capture all avenues of readership. For example, abstract views on PubMed could not be quantified, and full-text versions of the article may have been accessed through repositories and the study authors.

Finally, while a difference in Altmetric scores was only one outcome of interest, SoMe promotion in and of itself impacts this outcome. It is unsurprising that the CJEM articles with the highest Altmetric scores were those that received more aggressive SoMe promotion.

\section{CONCLUSION}

The abstracts of articles promoted using podcasts and infographics were viewed more often than those promoted only on CJEM SoMe accounts and achieved higher Altmetric scores. However, full-text readership did not change, suggesting that this dissemination did not lead to a detailed review of the articles by readers directed to them through SoMe promotion. Randomized studies are required to overcome confounding to determine the effectiveness of these strategies for increasing readership. The preliminary results of the SoMe Team's promotional strategies are promising.

Competing interests: None declared.

\section{REFERENCES}

1. Li LC, Grimshaw JM, Nielsen C, et al. Evolution of Wenger's concept of community of practice. Implement Sci 2009;4(1):11, doi:10.1186/1748-5908-4-11.

2. Wenger E. Communities of practice: learning, meaning, and identity. Cambridge, UK: Cambridge University Press; 1990.

3. Thoma B, Paddock M, Purdy E, et al. Leveraging a virtual community of practice to participate in a survey-based study: a description of the METRIQ Study Methodology. Acad Emerg Med Educ Train 2017;1(2):110-3, doi:10.1002/ aet2.10013.

4. Thoma B, Mohindra R, Artz JD, et al. CFEM and the changing landscape of medical education and knowledge translation. CFEM 2015;17(2):184-7, doi:10.1017/cem. 2015.16.

5. Chan T, Trueger NS, Roland D, et al. Evidence-based medicine in the era of social media: scholarly engagement through participation and online interaction. CFEM 2017; epub, doi:10.1017/cem.2016.407.

6. Mallin M, Schlein S, Doctor S, et al. A survey of the current utilization of asynchronous education among emergency medicine residents in the United States. Acad Med 2014; 89(4):598-601, doi:10.1097/ACM.0000000000000170.

7. Purdy E, Thoma B, Bednarczyk J, et al. The use of free online educational resources by Canadian emergency medicine residents and program directors. Can 7 Emerg Med 2015;17(2):101-6, doi:10.1017/cem.2014.73.

8. Lulic I, Kovic I. Analysis of emergency physicians' Twitter accounts. Emerg Med 7 2013;30(5):371-6, doi:10.1136/ emermed-2012-201132.

9. Bigham B. The "top five changes" project: 2015 AHA guidelines on CPR + ECC update infographic series. CanadiEM; 2015. Available at: https://canadiem.org/ the-top-five-changes-project-2015-aha-guidelines-update-cprecc-infographic-series/ (accessed 8 July 2017).

10. Lin M, Thoma B, Trueger NS, et al. Quality indicators for blogs and podcasts used in medical education: modified Delphi consensus recommendations by an international cohort of health professions educators. Postgrad Med 72015 ; 91(1080):546-50, doi:10.1136/postgradmedj-2014-133230.

11. Thoma B, Chan TM, Paterson QS, et al. Emergency medicine and critical care blogs and podcasts: establishing an international consensus on quality. Ann Emerg Med 2015;66(4): 396-402.e4, doi:10.1016/j.annemergmed.2015.03.002.

12. Chan T, Thoma B, Krishnan K, et al. The derivation of two simplified critical appraisal scores for use by trainees to evaluate online educational resources: a METRIQ study. West 7 Emerg Med 2016;17(5):574-84, doi:10.5811/ westjem.2016.6.30825.

13. Chan TM, Grock A, Paddock M, et al. Examining reliability and validity of an online score (ALiEM AIR) for rating free 
open access medical education resources. Ann Emerg Med 2016;68(6):729-35, doi:10.1016/j.annemergmed.2016.02.018.

14. Fox CS, Bonaca MP, Ryan JJ, et al. A randomized trial of social media from circulation. Circulation 2015;138:28-33, doi:10.1161/CIRCULATIONAHA.114.013509.

15. Fox CS, Gurary EB, Ryan J, et al. Randomized controlled trial of social media: effect of increased intensity of the intervention. 7 Am Heart Assoc 2016;5(5):1-9, doi:10.1161/JAHA.115.003088.

16. Hawkins MC, Hunter M, Kolenic GE, et al. Social media and peer-reviewed medical journal readership: a randomized prospective controlled trial. 7 Am Coll Radiol 2017;14(5):596602, doi:http://dx.doi.org/10.1016/j.jacr.2016.12.024.

17. Purdy E, Thoma B, Milne K, et al. SGEM Hot Off the Press: hypertonic saline in severe traumatic brain injury: a systematic review and meta-analysis of randomized controlled trials. CFEM 2016;18(5):379-84, doi:10.1017/cem.2016.374.

18. McKenna P, Thoma B, Milne K, et al. SGEM Hot Off the Press: ultrasound during critical care simulation: a randomized crossover study. Can 7 Emerg Med 2016;16(4):1-5, doi: $10.1017 / \mathrm{cem} .2016 .380$.

19. Trueger NS, Thoma B, Hsu CH, et al. The Altmetric score: A new measure for article-level dissemination and impact. Ann Emerg Med 2015;66(5):549-53, doi:10.1016/j. annemergmed.2015.04.022.

20. Page View. Wikipedia. Available at: https://en.wikipedia.org/ wiki/Page_view (accessed 5 July 2017).

21. Pathman DE, Konrad TR, Freed GL, et al. The awareness-toadherence model of the steps to clinical guideline compliance. The case of pediatric vaccine recommendations. Med Care 1996;34(9):873-89, doi:10.1097/00005650-199609000-00002.

22. Diner BM, Carpenter CR, O'Connell T, et al. Graduate medical education and knowledge translation: role models, information pipelines, and practice change thresholds. Acad Emerg Med 2007;14(11):1008-14, doi:10.1197/j.aem.2007. $\underline{07.003 .}$
23. Carpenter CR, Sherbino J. How does an "opinion leader" influence my practice? Can 7 Emerg Med 2010;12(5):431-4, doi:10.1016/j.biotechadv.2011.08.021.

24. Ibrahim AM, Lillemoe KD, Klingensmith ME, et al. Visual abstracts to disseminate research on social media: a prospective, case-control crossover study. Ann Surg 2017; epub, doi: doi:10.1097/SLA.0000000000002277.

25. Prince $M$. Does active learning work? A review of the research. 7 Eng Educ 2004;93(3):223-32, doi:10.1002/j.21689830.2004.tb00809.x.

26. Linton DL, Pangle WM, Wyatt KH, et al. Identifying key features of effective active learning: the effects of writing and peer discussion. CBE-Life Sci Educ 2014;13(3):469-77, doi:10.1187/cbe.13-12-0242.

27. Michael J. Where's the evidence that active learning works? Adv Physiol Educ 2006;30(4):159-67, doi:10.1152/advan. 00053.2006.

28. Chan TM, Thoma B, Radecki R, et al. Ten steps for setting up an online journal club. 7 Contin Educ Health Prof 2015; 35(2):148-54, doi:10.1002/chp.

29. Lin M, Joshi N, Hayes BD, et al. Accelerating knowledge translation: reflections from the online ALiEMAnnals Global Emergency Medicine Journal Club Experience. Ann Emerg Med 2017;69(4):469-74, doi:10.1016/j. annemergmed.2016.11.010.

30. Wenger E, McDermott R, Snyder WM. Cultivating communities of practice. Boston, MA: Harvard Business School Press; 2002.

31. Broaddus A, Riddell J, Brown A, et al. Who are the most influential emergency physicians on Twitter? West 7 Emerg Med 2017;18(2):281-7, doi:10.5811/westjem.2016.11.31299.

32. Thoma B, Sanders JL, Lin M, et al. The Social media index: measuring the impact of emergency medicine and critical care websites. West $\mathcal{F}$ Emerg Med 2015;16(2):242-9, doi:10.5811/westjem.2015.1.24860. 